\title{
Loss of fingerprints: forensic implications
}

\author{
Tanuj Kanchan ${ }^{1}$ and Kewal Krishan ${ }^{2^{*}}$ (D)
}

\begin{abstract}
Fingerprints have been successfully used for identification purposes for more than a century and remained one of the most commonly recovered evidence at the scene of crime. Due to their uniqueness and individualistic characteristics, the fingerprints are considered as the most powerful and widely used biometric characteristic. 'Adermatoglyphia' is a very rare condition where loss of fingerprints occurs. The present communication attempts to discuss the details of adermatoglyphia and its implications in the identification and recognition of individuals.
\end{abstract}

Keywords: Fingerprints, Biometric technology, Adermatoglyphia, Forensic identification

\section{Introduction and background}

Biometrics is an integral part of our lives because of their utility as identification technologies in civil matters and in criminal investigations. Among the various methods employed in biometrics, fingerprinting popularly known as dactylography is the most commonly employed method of identification. Fingerprints are unique to individuals and no two individuals have been found to have similar fingerprints. Fingerprints appear in the intrauterine life and it is widely believed that they do not change during the life time of an individual. High degree of sensitivity and specificity thus, makes it the most popular method of identification in the modern day. In the times when fingerprint identification is used for attendance of the employees and secure entry into offices, immigration and security check for entry into another country, in financial transactions, and in identification by law enforcement agencies etc., loss of fingerprints can have serious implications. It is desirable that medical practitioners and investigators are made aware of the medical conditions where in fingerprinting as a reliable method of identification can appear to be imperfect.

\section{Adermatoglyphia and alterations of fingerprints}

Absence or loss of fingerprints has been reported as a very rare condition called 'adermatoglyphia', often referred to as 'immigration delay disease' (Villacorta 2011). Loss of fingerprints is associated with Handfoot syndrome (palmar-plantar erythrodysesthesia or

\footnotetext{
*Correspondence: gargkk@yahoo.com; kewalkrishan@pu.ac.in

${ }^{2}$ Department of Anthropology, Panjab University, Sector-14, Chandigarh 160

014 , India

Full list of author information is available at the end of the article
}

palmoplantar erythrodysesthesia or Chemotherapy-induced acral erythema), a common adverse effect of various chemotherapeutic agents (Al-Ahwal 2012). Cohen (2017) reported a drug associated adermatoglyphia in two women suffering from breast cancer who were treated with Capecitabine, an oral 5-fluorouracil prodrug. A similar case was reported by Chavarri-Guerra and Soto-Perezde-Celis (2015) where a breast cancer patient treated with Capecitabine was denied authorization to perform a banking transaction due to loss of fingerprints. In another such case (Mazza et al. 2017); a 60 years old man suffering from rectal adenocarcinoma and liver metastasis developed adermatoglyphia when treated with Capecitabine. This European resident was unaware of the loss of his fingerprints, and was detained at the US airport for several hours. Other complicated syndromes such as Naegeli syndrome; an inherited skin disorder and dyskeratosis congenital; a bone marrow disease are also shown to be associated with adermatoglyphia (Groeger 2011). Nousbeck et al. (2011) discovered a gene SMARCAD1 associated with the loss of fingerprints and suggested that absence of fingerprints is autosomal-dominant phenomenon that occurs due to a mutation of the skin specific isoform of SMARCAD1.

Apart from adermatoglyphia, epidermal ridge atrophy and alterations may be seen in many cases of coeliac diseases, dermatitis, leprosy and after exposure to radiation (Reddy 2003).

\section{Forensic implications and conclusion}

Adermatoglyphia and alterations of fingerprints can have serious medicolegal implications. In such a scenario, 
certification of the condition by the treating physician appears to be the way out to save the patient from any inconvenience. At the same time, the medical practitioners and forensic experts need to be cautious especially in the times when lawbreakers are known to make every effort to alter their fingerprints in an endeavor to conceal their identity. Whether the loss of fingerprints is temporary or permanent in these medical conditions is also important and something to closely watch for.

In situations of adermatoglyphia, occupational disappearance of fingerprints (in case of bricklayers and people whose job involves working with calcium oxide or lime) and intentionally alterations of fingerprints by any means such as burning of fingertips and deeper cuts, surgical means etc. (Harmon 2009), the forensic practitioners need to be extra vigilant and watch whether these alterations have gone deep under the skin and damaged the fingerprint ridges or is it a temporary damage where the fingerprints/ ridges will readily emerge on the finger balls after few days of the momentary damage. The forensic scientists should also rely upon alternative methods for identification like face recognition, iris or retinal scans can be utilized for identification in cases where fingerprint identification is difficult/ questioned. In the present world, where fingerprints as a biometric technology has been in use in a variety of government and private organizations, aviation and immigration, office access, military, operation of bank accounts, computers and mobile phone access and so on; the loss of fingerprints may have serious implications.

\section{Acknowledgements}

None declared

\section{Funding}

No funding source

Availability of data and materials

Not applicable in this case as so primary data has been used in the manuscript.

\section{Authors' contributions}

TK and KK conceived the idea of writing this communication. TK, KK wrote the initial draft of the manuscript. Both authors read and approved the final manuscript.

\section{Ethics approval and consent to participate}

There is no need for the ethical approval as no research has been conducted in this manuscript.

\section{Consent for publication}

Not applicable

Competing interests

The authors declare that they have no competing interest.

\section{Publisher's Note}

Springer Nature remains neutral with regard to jurisdictional claims in published maps and institutional affiliations.

\section{Author details}

'Department of Forensic Medicine and Toxicology, All India Institute of Medical Sciences, Jodhpur, India. ${ }^{2}$ Department of Anthropology, Panjab University, Sector-14, Chandigarh 160 014, India.

Received: 16 November 2017 Accepted: 2 February 2018

Published online: 12 February 2018

\section{References}

Al-Ahwal MS (2012) Chemotherapy and fingerprint loss: beyond cosmetic. Oncologist 17(2):291-3. Am J Hum Genet 89(2):302-307. https://doi.org/10, 1016/j.ajhg.2011.07.004

Chavarri-Guerra Y, Soto-Perez-de-Celis E (2015) Images in clinical medicine. Loss of fingerprints. N Engl J med 372(16):e22

Cohen PR (2017) Capecitabine-associated loss of fingerprints: report of Capecitabine-induced Adermatoglyphia in two women with breast cancer and review of acquired Dermatoglyphic absence in oncology patients treated with Capecitabine. Cureus 9(1):e969. https:/doi.org/10.7759/cureus.969

Groeger L (2011). Tip off: solving the curious case of the missing fingerprints, Scientific American- A news item, Scientific American, Available at https://www. scientificamerican.com/article/missing-fingerprints/ (Accessed on 23 Oct 2017)

Harmon K (2009). Can you lose your fingerprints? Scientific American- a news item, scientific American, available at https://www.scientificamerican.com/ article/lose-your-fingerprints/ (Accessed on 27 Oct 2017).

Mazza C, Slimano F, Visseaux L, Ordan MA, Botsen D, Grange F, Bouche O (2017) Capecitabine and adermatoglyphia: trouble in border. J Eur Acad Dermatol Venereol 31(6):e283-e284. https://doi.org/10.1111/jdv.14045

Nousbeck J, Burger B, Fuchs-Telem D, Pavlovsky M, Fenig S, Sarig O, Itin P, Sprecher E (2011) A mutation in a skin specific isoform of SMARCAD1 causes autosomal-dominant adermatoglyphia. Am J Hum Genet 89(2):302-307

Reddy KSN (2003) The essentials of forensic medicine and toxicology. 22nd edition, Hyderabad: K Suguna Devi (Publisher).

Villacorta N (2011) The mystery of the missing fingerprints. Science news, available at: http://www.sciencemag.org/news/2011/08/mystery-missingfingerprints (Accessed 23 Oct 2017).

\section{Submit your manuscript to a SpringerOpen ${ }^{\circ}$ journal and benefit from:}

- Convenient online submission

Rigorous peer review

- Open access: articles freely available online

- High visibility within the field

- Retaining the copyright to your article

Submit your next manuscript at $\boldsymbol{\nabla}$ springeropen.com 